\title{
METODE PEMBELAJARAN PERMAINAN BOLA TANGAN DENGAN MENGGUNAKAN LATIHAN LADDER DRILL HOP SCOTCH PENGARUHNYA TERHADAP KEMAMPUAN AGILITY BERMAIN BOLA TANGAN
}

\author{
Ujang Rohman \\ Program Studi Pendidikan Kepelatihan Olahraga \\ ujangroh64@unipasby.ac.id
}

\begin{abstract}
This research is motivated by the fact that teaching in activities Students of the 2015 Sports Coaching Education, the Teaching and Education Faculty of the University of PGRI Adi Buana Surabaya the delivery of training materials less than the maximum, so that learners become passive and processes running less interesting extracurricular activities. Agility on hand ball sport is a absolut needs wich is must be had by all of hand ball's atletes. Formulation of the problem in this research is "Hand ball learning method using training ladder drill hop scotch effect on ability materials to play hand ball" The goal is to determine the presence or absence of ladder drill hopscotch training for agility on hand ball game on boy students $18^{\text {th }}$ grade of student of 2015 Sports Coaching. Agility is ability of someone to move faster and turn the navigate with agile. Agility is a combine of speed, strength, balance, flexibility and coordination. In this study to measure the agility use the instrumen of research zig-zag run test.. Subjects in this study consisted of 15 boy students. The method used for this study is one group pretest-posttest design. Data collection techniques using the test. Results of the t test obtained by value $t=6,795$ and while $t$ table with significance level of $\alpha=5 \%$ (0.05) 1.761. Thus $t$ count $>t$ table is $6,795>1.761$. This means that by using ladder drill hopscotch training influence the agility of hand ball game.
\end{abstract}

Keywords: ladder drill, agility

\section{PENDAHULUAN}

Aktivitas olahraga saat ini benar-benar sudah menjadi bagian dari kebutuhan masyarakat, baik pada masyarakat atau golongan dengan sosial ekonomi yang rendah sampai yang paling tinggi. Kegunaan akan pentingnya berolahraga sangat dirasakan oleh masyarakat berupa latihan olahraga yang teratur dalam rangka untuk kesegaran dan kesehatan jasmani. Seseorang melakukan olahraga dengan tujuan untuk mendapatkan kesegaran jasmani, kesehatan maupun kesenangan bahkan ada yang sekadar hobi. Berbagai aktivitas olahraga yang dilakukan dan diselenggarakan oleh masyarakat yang memiliki tujuan sama yaitu menjaga tingkat kesegaran jasmani.

Aktivitas olahraga ini tidak saja dilakukan di lingkungan masayarakat, tetapi juga dilakukan dilingkungan formal seperti di sekolah sesuai dengan kurikulum. Pada kurikulum di sekolah terutama dalam mata pelajaran 
Pendidikan Jasmani, olahraga dan kesehatan (PJOK) dalam proses pembelajaran materi pelajaran yang diajarkan salah satunya permainan bola tangan. Permainan bola tangan ini tidak hanya di ajarkan di sekolah tetapi juga di ajarkan di perguruan tinggi keolahragaan sebagai salah satu mata kuliah wajib yang harus di tempuh..

Permainan bola tangan adalah olahraga beregu di mana setiap regu bermain dengan jumlah pemain masingmasing 7 (6 pemain dan 1 penjaga gawang) yang berusaha memasukkan sebuah bola ke gawang lawan dengan cara berjalan atau berlari sambil memantul-mantulkan bola ke lantai/ke tanah. Permainan bola tangan dapat ditelusuri sejarahnya.

Pada zaman Yunani Kuno permainan bolatangan sudah dimainkan walaupun dengan peraturan yang masih kuno. Permainan "Urania" yang dimainkan oleh orang-orang Yunani kuno (yang digambarkan oleh Homer dan Odyssey) dan "harpaston yang dimainkan oleh orang-orang Romawi yang bernama Claudius Galenus tahun 130 sampai 200 Masehi. Pada tahun 1928 International Amateur Handball Federation (IAHF) bertepatan dengan Olimpiade Amsterdam dengan ketua Avery Brundage dari Amerika.

Federasi Bola Tangan Asia (Asian Handball Federation) terbentuk pada tahun 1974, pada waktu berlangsungnya
Asian Games di kota Teheran. Kemudian pada tahun 1976 federasi ini dikukuhkan secara resmi di Kuwait. Sedangkan induk organisasi tingkat nasional di negara kita menurut akta notaris tentang Pendirian Asosiasi Bola Tangan Indonesia resmi berdiri tanggal 16 Agustus 2007.

Pada tanggal 5 Juni 2009, ABTI resmi sebagai Full Member International Handball Federation (IHF). Pada permainan bola tangan ada berbagai teknik yang harus dikuasai oleh pemain dan pada saat permainan sebagian teknik tersebut merupakan ciri atau karakteristik bentuk permainannya. Untuk menunjang kemampuan teknik bermain bola tangan tersebut, maka perlu adanya dukungan kemampuan fisik yang memadai baik itu saat latihan maupun saat bermain. Salah satu komponen kondisi fisik yang sangat dominan dalam permainan bola tangan yaitu agility seorang pemain. Untuk meningkatkan agility pemain harus ada metode latihan yang tepat, salah satunya adalah metode latihan Ladder Drill Hop Scotch.

Latihan yang berasal dari kata practice adalah aktivitas untuk meningkatkan keterampilan (kemahiran) berolahraga dengan menggunakan berbagai peralatan sesuai dengan tujuan dan kebutuhan cabang olahraganya. Pengertian latihan yang berasal dari kata exercises adalah perangkat utama dalam 
proses latihan harian untuk meningkatkan kualitas fungsi sistem organ tubuh manusia, sehingga mempermudah olahraga dalam penyempurnaan geraknya. Pengertian latihan yang berasal dari kata training adalah penerapan dari suatu perencanaan untuk meningkatkan kemampuan berolahraga yang berisikan materi teori dan praktik, metode, dan aturan pelaksanaan sesuai dengan tujuan dan sasaran yang akan dicapai (Sukadiyanto, 2011).

Latihan Ladder drill merupakan latihan yang menggunakan tangga drill sebagai alat untuk latihan. Ladder merupakan salah satu bentuk alat latihan fisik yang meyerupai anak tangga yang di letakkan pada bidang datar atau lantai. Latihan ladder drill membantu dalam improvisasi berbagai aspek gerakan., meningkatkan keseimbangan, daya tahan otot, waktu reaksi dan koordinasi antara berbagai bagian tubuh, dan agar pemain dapat mengubah arah lebih cepat, meski dalam kecepatan tinggi (saat sprint). Dalam penelitian ini peneliti menggunakan metode latihan ladder drill hop scotch.

Berdasarkan latar belakang di atas maka penulis ingin meneliti mengenai: "Metode pembelajaran bola tangan dengan menggunakan latihan ladder drill hop scotch pengaruhnya terhadap kemampuan agility bermain bola tangan.

\section{METODE PENELITIAN}

Penelitian ini merupakan penelitian eksperimen lapangan, dimana penelitian ini mengenai mencari dampak atau sebab akibat dari suatu perlakuan latihan yang berbentuk program yang dilatihkan. Menurut Arikunto (1990:272), penelitian eksperimental merupakan penelitian yang yang bertujuan 
mengetahui akibat yang terdapat pada subjek penelitian. Dalam penelitian ini paling sedikit dapat dilakukan dalam satu kondisi yang dimanipulasi. Sementara kondisi yang lain dianggap konstan, kemudian pengaruh perbedaan kondisi atau variabel tersebut dapat diukur.

Subjek yang dijadikan objek penelitian adalah mahasiswa Pendidikan Kepelatihan Olahraga angkatan 2015 yang memprogram mata kuliah bola tangan yang dilaksanakan pada semester ganjil tahun akademik 2017/2018.

Penelitian yang dilakukan oleh peneliti adalah penelitian eksperimen lapangan dengan menggunakan pendekatan kuantitatif. Desain penelitian yang digunakan adalah menggunakan rancangan penelitian eksperimen. Hal ini dapat terjadi, karena tidak adanya variabel kontrol, dan sampel dipilih secara random" (Sugiyono, 2013). Oleh karena itu rancangan penelitian menggunakan onegroup pretest-posttest design. Desain ini dapat digambarkan (Sugiyono, 2013) sebagai berikut:

\begin{tabular}{|c|c|c|c|}
\hline Kelompok & $\begin{array}{c}\text { Pretes } \\
t\end{array}$ & $\begin{array}{c}\text { Perlakua } \\
\mathrm{n}\end{array}$ & $\begin{array}{c}\text { Posttes } \\
t\end{array}$ \\
\hline $\begin{array}{c}\text { Exsperime } \\
\mathrm{n}\end{array}$ & O1 & $X$ & $\mathrm{O} 2$ \\
\hline $\begin{array}{l}\text { Ket: } \\
\mathrm{X}=\text { Trear } \\
\mathrm{O} 1=\text { Prete }\end{array}$ & & & \\
\hline
\end{tabular}

$$
\mathrm{O} 2 \text { = Postest }
$$

Populasi adalah wilayah generalisasi yang terdiri atas obyek/subyek yang mempunyai kualitas dan karakteristik tertentu yang ditetapkan oleh peneliti untuk dipelajari dan kemudian ditarik kesimpulannya. Populasi dalam penelitian ini adalah mahasiswa Program Studi Pendidikan Kepelatihan Olahraga, FKIP Universitas PGRI Adi Buana Surabaya. Sedangkan yang dijadikan sampel adalah Mahasiswa Putra Angkatan 2015 Program Studi Pendidikan Kepelatihan Olahraga.

Pengambilan subjek penelitian dilakukan dengan random sampling yang termasuk dalam probability sampling karena dalam penelitian ini anggota populasinya homogen (Sugiyono, 2013).

Teknik pengumpulan data menggunakan tes dan pengukuran ZigZag Run. Metode latihan ladder drill yang dijadikan treatment adalah latihan hop scotch latihan ini digunakan untuk melatih kemampuan agility. Prosedur pengambila data dilakukan dengan melakukan pretest dan posttest agility menggunakan instrumen tes zig-zag run untuk mendapatkan hasil yang akurat sesuai kemampuan yang akan di ukur.

Tes zig-zag run untuk mengetahui diharapkan pengaruh latihan ladder drill hop scotch terhadap agility pemain bola tangan. Kriteria pengujian hipotesis 
dengan menggunakan analisis statistik uji t. Penelitian ini dilakukan dengan membandingkan data hasil pretest dan posttest setelah perlakuan. Apabila nilai thitung lebih lebih kecil dari nilai tabel maka Ho (hipotesis nol) diterima dan jika nilai $t$ hitung lebih besar dari nilai $t$ tabel maka Ho ditolak.

\section{HASIL PENELITIAN}

Berdasarkan hasil rangkaian tes agility yang telah dilaksanakan dengan menggunakan instrumen tes zig-zag run didapatkan informasi berupa data hasil pretest dan postest tentang perkembangan variabel kemampuan agility. Selanjutnya data tersebut di analisis menggunakan analisis statistik deskriptif uji t.

Hasil nilai rata-rata dan simpangan baku agility dapat di lihat pada tabel berikut:

Tabel. Hasil Nilai Rata-rata dan SD Agility

\begin{tabular}{ccc}
\hline Agility & Pretest & Postest \\
\hline Mean & 9.28 & 8.60 \\
\hline SD & 2.3 & 1.89 \\
\hline
\end{tabular}

Nilai rata-rata agility pretest sebesar 9.28 dan postest sebesar 8.60 berarti adalah selisih peningkatan catata waktu sebesar 0.68 dari hasil perlakuan latihan. Sedangkan berdasarkan hasil perhitungan statistik uji $t$, dapat diketahui bahwa hasil $t$ hitung sebesar 6,795 sedangkan $t$ tabel sebesar 1.761 dengan derajat kebebasan $\mathrm{df}=\mathrm{n}-1(\mathrm{df}=$
$15-1=14)$ dan taraf signifikan $\alpha=0.05$ (95\%). Berdasarkan kriteria pengujian hipotesis dapat disimpulkan bahwa $\mathrm{t}$ hitung $>\mathrm{t}$ tabel) $(6,795>1,761)$ artinya Ho ditolak dan Ha diterima. Kesimpulannya "Metode pembelajaran bola tangan dengan menggunakan latihan ladder drill hop scotch ada pengaruhnya terhadap kemampuan agility bermain bola tangan. Hasil analisis dapat di lihat pada tabel berikut

Tabel. Hasil Analisis Uji t Tes Agility Pemain Bola Tangan

\begin{tabular}{cccc}
\hline Variabel & $\mathrm{t}_{\text {hitung }}$ & $\mathrm{t}$ tabel & Hasil \\
\hline Agility & 6,795 & 1,761 & Signifikan \\
\hline
\end{tabular}

\section{PEMBAHASAN}

Setelah data hasil penelitian diolah dengan menggunakan uji statistik deskriptif uji $t$ sebelum perlakukan (pretest) dan sesudah perlakuan (postest) ada perubahan yang diakibatkan oleh hasil perlakuan latihan ladder drill hop scotch. Berdasarkan hasil analisis data menunjukkan nilai $\mathrm{t}$ hitung sebesar 6,795 dan nilai $t$ tabel sebesar 1,761, artinya nilai $t$ hitung lebih besar dibanding nilai $t$ tabel. Jadi dapat disimpulkan bahwa ada pengaruh pengaruh latihan ladder drill hop scoth terhadap kemampuan agility dalam permainan bola tangan. Sedangkan besarnya persentase perubahan perlakuan saat pretest dengan postest didapatkan hasil yang 
menunjukkan besarnya peningkatan 7,08\%..

Hal ini disebabkan karena variabel bebas yang berpengaruh pada variabel terikat di akibatkan oleh program latihan yang diberikan secara intensif dan kontinyu. Latihan yang diberikan selama 6-8 minggu akan memberikan peningkatan yang cukup berarti (Pate, 1984). Selain itu frekuensi latihan 3 kali seminggu akan meningkatkan kualitas kondisi fisik yang pada akhirnya akan meningkatkan kemampuan agility (Broosk, 2014).

Interpretasi hasil penelitian yang membahas mengenai: "Metode pembelajaran permainan bola tangan dengan menggunakan latihan ladder drill hop scotch pengaruhnya terhadap kemampuan agility bermain bola tangan" yang dijadikan objek penelitian adalah mahasiswa Pendidikan Kepelatihan Olahraga PKO) angkatan 2015. FKIP Universitas PGRI Adi Buana Surabaya. Hasil penelitian menunjukkan bahwa latihan Ladder Drill Hop Scoth berpengaruh terhadap kemampuan agility dalam bermain bola tangan.

Adanya pengaruh tersebut terjadi akibat latihan yang disebabkan oleh adaftasi fisiologis dari perubahan anatomis otot dan sistem saraf tubuh. Perubahan yang ada dalam otot tersebut menyebabkan peningkatan aktin, miosin, miofibril, kapiler dan sarkoplasma (Fox, Matehws, 1988). Peningkatan ini menyebabkan perubahan kimia yang terjadi pada otot sehingga dapat meningkatkan ATP-PC yang berperan dalam kontraksi otot. Oleh karena itu kondisi fisik yang sangat beran penting dalam permainan bola tangan salah satunya adalah kemampuan agility pemain bola tangan. Pemain dituntut mampu berlari dengan lincah terutama saat melakukan penyerangan ke daerah lawan dan mempertahankan bola serangan lawan.

Di lihat dari karakteristik latihan Ladder Drill Hop Scoth secara fisiologis otot-otot yang terlibat adalah otot-otot pada anggota badan bagian bawah (lower extremity) seperti: otot gluteus maximus, biceps femoris, semitendinosus, gastrocnemeus, soleus, plantaris, tibialis dan peroneus anterior. Pada dasarnya otot-otot tersebut yang sangat berperan dalam melakukan gerakan kesegala arah tanpa kehilangan keseimbangan yang berarti.

Hal ini memberikan gambaran bahwa meningkatnya kemampuan agility khususnya dalam permainan bola tangan membutuhkan gerakan lompatlompat dengan arah yang beraturan berdasarkan prinsip kekhususan dalam latihan dimana beban latihan disesuaikan dengan gerakan dasar pada permainan bola tangan yang banyak melibatkan kelompok otot anggota badan bagian bawah. Kontraksi otot dan rangsang saraf berdaya guna apabila menggunakan beban sedang dan bentuk 
latihan yang bersifat isotonik (Clark, 2006), kontraksi otot maksimum terjadi bila pada saat panjang optimum dirangsang untuk berkontraksi, hal ini dikarenakan tersimpannya energi elastik pada otot yang diregang dengan cepat akan dikeuarkan lagi pada saat kontraksi isotonik.

\section{SIMPULAN DAN SARAN}

\section{Simpulan}

Berdasarkan dari hasil analisis data maka, simpulan hasil peneliti adalah sebagai berikut:

1. Metode pembelajaran bola tangan dengan menggunakan latihan ladder drill hop scotch ada pengaruhnya terhadap kemampuan agility bermain bola tangan. Hal tersebut terbukti dari hasil perhitungan $\mathrm{t}$ hitung $>\mathrm{t}$ tabel yaitu $6,795>1,761$.

2. Besarnya pengaruh dalam penelitian ini dari hasil perhitungan signifikansi diperoleh nilai peningkatan persentase agility hasil dari selisih tes awal (pree test) dengan tes akhir (post test) sebesar 70.8 atau 7,08\%.

\section{Saran}

Berdasarkan hasil penelitian, maka saran yang dapat di sampaikan adalah sebagai berikut:

1. Sebelum latihan ladder drill dijalankan hendaknya pelatih memberikan perhatian dan arahan kepada testee agar tidak terjadi kesalahan saat latihan berlangsung, sehingga aktifitas dapat terlaksana dengan efektif dan efisien.

2. Untuk peneliti berikutnya disarankan apabila menggunakan metode latihan ladder drill harus digunakan langkahlangkah sesuai petunjuk pelaksanaan perlakuan (treatment)

3. Apabila dalam memberikan latihan hendaknya dipersiapkan sarana dan prasarananya dengan matang dan sesuai dengan langkah-langkahnya agar memberikan pengaruh yang positif dan signifikan terhadap kemampuan peserta didik

\section{DAFTAR PUSTAKA}

Arikunto, Suharsimi. 2013. Prosedur Penelitian. Jakarta: PT. Rineka Cipta.

Bompa, O.T. 2006. Theory and methodology of training: Surabaya: Airlangga University.

Brooks, A., Fahey, TD., 2014. Exercise Physiology Human Bioenergetics and It's Aplications. John Wiley and Sons Inc. New York.

Clark, K., Hall, LK., Wilson, PK., 2008., Figure Finder Fat-0-Mater Skinfolld Calipers. La Crosse Exercises Program, University of Winconsin, La. Cross.

Fox., EL, Mathew, DK, 19988., The Physological Basis of Physical 
Education and Athletics. Saunders Santoso, G. 2007. Metodologi Penelitian. College Publishing, Philadelphia. Jakarta: Perpustakaan Nasional. Maksum, Ali. 2009. Statistika. Surabaya. Sugiyono. 2013. Metode Penelitian Surabaya. Universitas Negeri Surabaya. Pendidikan. Bandung: Alfabeta.

Sukadiyanto, 2011. Pengantar teori dan Pate, RR., Mc Clenaghan., B. Rottella, R., Metodelogi Melatih Fisik. Bandung: 1984. Scientific Fundation of CV. Lubuk Agung.

Coaching. Saunders College Publishing, Philadelphia. 